\title{
News Podcast Usage in Promoting Political Participation in Korea ${ }^{1}$
}

\author{
By Changho Lee*
}

\begin{abstract}
Based on an online survey of 734 news podcast users in Korea, this study analyzed how motivations for podcast use and news podcast variables affected offline and online political participation. The results showed that any motivation did not have a significant effect on offline and online participation. Rather, discussions about issues transmitted through news podcasts were a positive predictor of online participation as well as offline participation. The discussion was also a mediator in the relationship between the time spent on a news podcast and offlinelonline political participation. That is, news podcast use enhanced political discussions, which promoted participation offline and online. Overall, these results indicate that discussions are important in the mobilization of political participation in the era of podcast.
\end{abstract}

Keywords: podcast, news podcast, political discussion, online participation, offline participation

\section{Introduction}

Podcasts are audio files that can be downloaded or streamed from a smartphone at no cost (Perks and Turner, 2019). Podcasting came of age in 2005 and its emergence was solidified in 2015 when Apple upgraded to iTunes 4.9 (Bottomley, 2015). It is becoming popular with the development of audio technology and the spread of smartphone. Easy access to downloads and developments in technology have facilitated prominent a position of podcasts in the digital cultural industries (Vrikki and Malik, 2019). They enable an audience to time-shift: People can download them and tune in whenever they want (McClung and \& Johnson, 2010).

In the United States, 32\% of Americans aged 12 and older have listened to podcast in the past month in 2019 while it was only 9\% in 2008 (Pew Research Center, 2019). According to Podtrac, which released top 20 podcasts rankings every month, as of August 2019, <The Daily> run by The New York Times ranked first, followed by $<$ Stuff You Should Know $>$ (iHeartRadio), $<$ This American Life $>$ (This American Life/Serial), $<$ The Ben Shapiro Show $>$ (Daily Wire), and $<$ Up First $>$ (NPR) (Podtrac, 2019). Korean people are also heavy listeners of podcasts. According to Podbbang (www.podbbang.com), a platform of podcast in Korea, as of August 2019, there are about 23,000 podcasts including news, music, travel, sports, books, etc. Among them, news podcasts dealing with political

\footnotetext{
*Research Fellow, National Youth Policy Institute, Korea.

${ }^{1}$ This research is based on Podcast Journalism Study sponsored by Korea Press Foundation in 2018.
} 
matters and public issues are very popular. Out of 22 countries, the number of people who listened to podcast for the past month was highest in Korea (58\%), followed by Hong Kong (55\%), Taiwan (47\%), and Spain (40\%) (Korea Press Foundation and Reuters Journalism Institute, 2018).

To begin with, most of the Korean political podcasts only had an audio format and were critical of the existing political power. Especially, $<$ Naneun Ggomsuda $>$ meaning "I am a pretty-mined creep", a news podcast established in 2011, played an important role in criticizing the conservative government and revealing wrongdoings of political leaders. Using humor, satire, and parody, the podcast delivered news with interest and entertainment (Park, 2017). At that time when the podcast started, the mainstream media were controlled by the government. Thus, most of them were silenced on the criticism of government policy whereas $<$ Naneun Ggomsuda $>$ played a watchdog role. Therefore, this podcast was liked by many people with progressive political interests. Around December 2012, it was terminated, but four members of hosts created other news podcasts and continued their work. Later, conservative groups set up a number of video podcasts through YouTube channel to promote their political agenda and ideology. More specifically, these podcasts were targeted to older conservatives over 60s (Chung, 2019). Many of conservative podcasts were established in 2017 when the former president Geun-hye Park was impeached and Jae-in Moon, a liberal figure was elected as a new president of Korea. They argued that president Park was not guilty although she was convicted by Supreme Court and sentenced to jail. Accordingly, they were very active in transmitting conservative ideology and thoughts. Because of this spread of conservative news podcasts, the ideological conflicts between progressive and conservative groups to promote each political position are becoming fierce in Korea.

Although a lot of podcasts have been created over the past few years, many studies were focused on aforementioned $<$ Naneun Ggomsuda $>$ because it played an important role in watching and criticizing government (Lee and Hwang, 2013; Lee and Keum, 2012; Lee and Ryu, 2013). As a result, there are few studies addressing the relationship between news podcast and political participation in the situation of rapid diffusion of podcast.

Therefore, this study analyzes how a news podcast promotes offline and online political participation in the context of motivations for the medium and its use. Especially, drawing on the communication mediation model, the study investigates the mediating role of political discussions in the relationship between news podcast use and political participation.

\section{Theoretical Background}

\section{Motivations for Using Podcasts and Political Participation}

Uses and gratifications approaches in communication focus on why and for what purpose people use media. Different motivations lead to different communication choices and behaviors (Rubin and Step, 2000). For example, 
Rubin and Step (2000) identified four motives for talk radio listening: pass time/habit, exciting entertainment, escapist relaxation, and information. They found that entertainment motive was associated with talk radio exposure while information and pass time motivation were predictors of behavioral effect, a sense that the host influenced the listener to talk to others about politics or vote for political candidates. The study of college students showed that interpersonal utility motive of Internet use was a predictor of Internet affinity and information seeking motive was associated with Internet satisfaction (Zizi and Rubin, 2000). That is, those who want to fulfill interpersonal needs through the Internet are more likely to be attracted by the Internet. In addition, the more students use the Internet to find information, the more they are satisfied with the medium.

Reasons for listening to podcasts are varied. Perks and Turner (2019) found that parasocial relationships formation with podcast hosts, multitasking, entertainment, and education or learning something new were main motives. Podcasts were also most commonly replacements for radio/music and television. Entertainment, time shifting, library building, advertising, and social aspects were primary motives of podcast listening (McClung and Johnson, 2010). Interestingly, podcast users supported companies that advertise on podcasts (advertising motive) and they talked with friends about podcasts they downloaded (social aspects motive). According to a web-based survey of 137 podcasters, their reasons to start podcasting include public creativity, performance/promotion, long tail (e.g., convenience and freedom of the medium), and entertainment (Markman and Sawyer, 2014). Independent podcasters saw podcasting as an alternative to traditional media and they regularly attended podcasting events.

In Korea where political podcasts are popular, motivations included not only entertainment but also information seeking such as alternative press function (Lee, 2017) and political interests (Hwang and Kim, 2012). That is, people listened to podcasts to find information which mainstream media did not cover. They also depended much on podcasts for political information and diverse viewpoints of public issues. Because podcasts provide deep explanation and analysis of specific issues important to society, people can learn about what is occurring within society easily. Accordingly, political motivations are much stronger among Korean users because news podcasts are very popular in this country.

Several studies showed that there was a positive relationship between motivations and political participation. For example, the amusement motivation (relaxation/killing time) for using podcast as well as informational one (pursuit of alternative information) was positively related to offline participation of Korean college students (Lee and Keum, 2012). The motive for amusement was also positively associated with online participation. This result indicates that entertainment motivation is important in promoting political participation. However, another study showed that the motivations for exchanging information with others obtained from podcast was a strong predictor of not only offline participation but also online participation (Lee and Hwang, 2013).

As shown above, there are few studies on the relationship between motivations of podcast use and political participation. Furthermore, the study results are not consistent. Thus, this study suggests the following research 
question.

RQ 1: What motivations are associated with political participation?

\section{Podcast and Political Participation}

Recently, many scholars have focused on the relationship between social media news consumption and online/offline political, civic engagement (Gil de Zúñiga et al., 2012; Hao et al., 2014; Yang and DeHart, 2016). Overall, general use of social media was not associated with participation whereas political use of Social Network Service (SNS) was a critical predictor of participation. According to a study of university students in China and Hong Kong, information seeking via SNS was positively related to online and offline discussion, which led to online political participation ( $\mathrm{Li}$ and Chan, 2017). Offline discussion mediated between information seeking and offline political participation. Another study of U.S. college students also found that political use of Twitter or Facebook was an important predictor of online political participation (Yang and DeHart, 2016). On the other hand, Twitter use and Facebook use were negatively related to it. This result indicates that news consumption for acquisition of current affairs is related to political participation, and therefore not the time spent on the media.

In addition to SNS, political podcasts are becoming a new source of information for political issues and contributed to enhancing and facilitating political participation, especially among young generation (Lee and Ryu, 2013; Song, 2012). Although there are limited number of studies on podcast, several studies have shown that there is a positive relationship between news podcast use and political participation. For example, Chadha and colleagues found that podcast was a strong predictor of online and offline political participation although their study focused on podcast in general, not on specific type of podcast such as politics and economy (Chadha et al., 2012). Lee and Ryu (2013) found that political podcast $<$ Naneun Ggomsuda $>$ use was positively related to political participation as well as political interest and efficacy of high school students and college students. The analysis showed that the podcast enhanced the political interests of high school students while it promoted political participation of college students.

Political discussion is also an important factor which can lead to political participation. It provides opportunities to learn information and ponder about public issues and reach common understanding (Valenzuela et al., 2011). It also promotes political efficacy. Political discussion with weak ties (acquaintances or strangers) was a mediator between news use and internal political efficacy (Ardèvol-Abreu et al., 2017). That is, the new information from the media fosters political discussion about issues, which lead to an increased self-perception of competence in participating in the democratic process. Political discussion with weak-ties and like-minded people were positively associated with online political participation (Valenzuela et al., 2011).

News podcast users are relatively young and progressive and are much 
interested in political issues (Min, 2014). Therefore, it is expected that news podcast use will lead to their active participation in society. Based on the previous literature, this study suggested the following hypotheses.

H1: The use time of news podcast is positively related to offline political participation.

$\mathrm{H} 2$ : The use time of news podcast is positively related to online political participation.

H3: Political discussion on issues transmitted through news podcast is positively related to offline political participation.

H4: Political discussion on issues transmitted through news podcast is positively related to online political participation.

\section{Communication Mediation Model}

Communication mediation model highlights the importance of political discussion in promoting political participation. This model articulates that campaign advertisements exposure stimulate information seeking via mass media, which in turn leads to interpersonal exchanges about politics (Cho et al., 2009). This reasoning process through discussion causes participatory activities. By integrating mass and interpersonal information channels, the model shows a process whereby news consumption yields various attitudinal and behavioral outcomes (Lee, 2012). Shah and colleagues found that informational media use encouraged citizen communication, which affected civic participation (Shah et al., 2007). Accordingly, this model places discussion among citizens in a mediating position between news consumption and civic engagement (Shah et al., 2017).

This model has been supported by many studies. For example, Lee (2012) analyzed the mediating role of interpersonal talk between late-night comedy viewing and political participation. As a result, discussion with neighbors, friends and family and the number of people with whom respondents talk about politics fully mediated the relationship. The study of Korean political news podcasts showed that they promoted political discussion via online/mobile media which in turn affected political participation in the presidential election in 2012 (Min, 2015). On the contrary, the mediating role of political discussion offline was not confirmed in this study. Recently, Zúñiga and colleagues (Gil de Zúñiga et al., 2019) examined the applicability of the citizen communication model across 19 countries. They found that news use and political discussion were related to political participation across countries. In addition, political discussion mediated the relationship between news and participation. In more democratic societies, discussion was positively associated with political participation. According to the study on university students in Taiwan, Hong Kong, and China, political discussion was a predictor of political efficacy, which in turn led to offline and online political participation (Chan et al., 2017). In the Hong Kong and China sample, political discussion mediated the relationship between political messaging on mobile and social media and 
online participation. However, there was no direct relationship between mobile news and social media news and political discussion.

Drawing on the communication mediation model, the following hypotheses were suggested.

H5: Political discussion will mediate between news podcast and offline political participation.

H6: Political discussion will mediate between news podcast and online political participation.

\section{Method}

\section{Sample}

This research is based on an online survey of 1,000 podcast users in Korea, which was conducted for a week in mid-July in 2018. The research company which has the most online panels conducted this survey. First, panels were asked to select channels including podcast, Africa TV, Naver audio clip, and other new media services in Korea, they used for the past one month. As a result, 6,859 people clicked the survey link and among them 2,771 respondents selected podcast. Out of 2,771 podcast users, 1,000 respondents could participate in the survey because the target sample size was 1,000 people. Quota sampling in consideration of gender and age was used to enhance the representativeness of the population. As a result, gender and age distribution of sample (male $51.2 \%$, female $48.8 \%$; 20s $21.9 \%$, 30s $23.1 \%$, 40s $27.7 \%$, 50s $27.3 \%$ ) were almost the same as that of population in Korea (male $51.2 \%$, female $48.8 \%$; 20s $21.9 \%$, 30s 23.4\%, $40 \mathrm{~s} 27.4 \%$, 50s $27.2 \%$ ).

Because this research was focused on news podcast, we used 734 respondents for the analysis, who said that they used news podcast at least once for the past one month. Of the sample, 401 (54.6\%) were males and 303 (45.4\%) were females: $135(18.4 \%)$ were in $20 \mathrm{~s}, 152(20.7 \%)$ were in $30 \mathrm{~s}, 224(30.5 \%)$ were in $40 \mathrm{~s}$, and $223(30.4 \%)$ were in $50 \mathrm{~s}$.

\section{Measures}

Dependent variables. Offline participation (5 items) was measured by whether respondents participated in the following activities for the past one year at the time of survey; demonstrations, signature campaign, boycott, voting and making a complaint call to government and public institutions. Items were rated on Yes (1) or No (0) and averaged for the analysis $(\mathrm{M}=2.20, S D=1.11)$. SNS participation (5 items) was measured by the extent to which respondents read political messages, posted their opinions about political issues, replied to others' messages, shared messages of other people and participated in online petition via SNS. Items were adapted from Bai (2015). Each item was rated from 1 (never) to 4(often) and averaged $(\alpha=.82, \mathrm{M}=2.30, S D=.65)$. 
Independent variables. Motivations for podcast use was composed of four factors, considering previous studies (Lee, 2017; Lee and Hwang, 2013; Hwang and Kim, 2012). Entertainment motivation indicates that people use podcast for amusement or pleasure while access motivation means that people get access to podcast easily. Information seeking motivation indicates that people use podcast to get information about social, political issues. Finally, alternative media motivation means that people depend on podcast to find information which cannot be found in mainstream media. Each factor comprised three items and was rated on a 5-point Likert scale ( $1=$ strongly disagree $\sim 5=$ strongly agree). To check whether items are consistent with each factor, we conducted confirmatory factor analysis. However, one item "I use podcast just to kill time" had a very low factor loading value $(0.162)$ in entertainment factor and was excluded from the analysis. As shown in Table 1, all the value of factor loadings indicated over 0.5 , which was acceptable. AVE (Average Variance Extracted) value was over 0.5 and CR (Composite Reliability) value was over 0.7 except for entertainment motivations. Although RMSEA value was a little more than criterion value (0.08), the value of CFI and TLI indicated over 0.9 , which was an acceptable level. Reliability coefficient was over 0.6 and it was acceptable.

Table 1. Confirmatory Factor Analysis of Motivations for Podcast Use

\begin{tabular}{|c|c|c|c|c|c|c|}
\hline Factor & $\begin{array}{l}\text { Item } \\
\text { (I use podcast } \\
\end{array}$ & $\begin{array}{l}\text { Factor } \\
\text { loading }\end{array}$ & SE & AVE & $\mathrm{CR}$ & $\alpha$ \\
\hline \multirow{2}{*}{ Entertainment } & For amusement & 0.745 & 0.025 & \multirow{2}{*}{0.496} & \multirow{2}{*}{0.663} & \multirow{2}{*}{0.654} \\
\hline & To comfort me & 0.662 & 0.029 & & & \\
\hline \multirow{3}{*}{ Access } & To listen to it at any time & 0.788 & 0.021 & \multirow{3}{*}{0.546} & \multirow{3}{*}{0.708} & \multirow{3}{*}{0.767} \\
\hline & To listen to it repeatedly & 0.599 & 0.027 & & & \\
\hline & To listen to it anywhere & 0.814 & 0.023 & & & \\
\hline \multirow{3}{*}{$\begin{array}{l}\text { Information } \\
\text { seeking }\end{array}$} & $\begin{array}{l}\text { To get information in detail } \\
\text { about social, political issues }\end{array}$ & 0.945 & 0.027 & \multirow{3}{*}{0.789} & \multirow{3}{*}{0.898} & \multirow{3}{*}{0.909} \\
\hline & $\begin{array}{c}\text { To get detailed explanations } \\
\text { and interpretations }\end{array}$ & 0.955 & 0.027 & & & \\
\hline & To know about recent issues & 0.750 & 0.027 & & & \\
\hline \multirow{3}{*}{$\begin{array}{l}\text { Alternative } \\
\text { media }\end{array}$} & $\begin{array}{c}\text { To know about issues which } \\
\text { cannot be found in } \\
\text { mainstream media }\end{array}$ & 0.874 & 0.029 & \multirow{3}{*}{0.586} & \multirow{3}{*}{0.713} & \multirow{3}{*}{0.826} \\
\hline & $\begin{array}{l}\text { To like unhindered criticism } \\
\text { about existing political } \\
\text { power }\end{array}$ & 0.721 & 0.032 & & & \\
\hline & To like straightforward talk & 0.690 & 0.031 & & & \\
\hline
\end{tabular}

Note: Chi-square $=438, d f=38, p<0.001, \mathrm{CFI}=0.938, \mathrm{TLI}=0.910, \mathrm{RMSEA}=0.103$

In addition to motivations, we measured news podcast in terms of use time and discussion. First, we asked respondents how much time they spent on listening to news podcast per day on average. This item is rated on a 5-point Likert Scale ( $1=$ less than 30 minutes $\sim 5=$ more than 2 hours). Discussion indicates how often they talk about political issues with people, which was transmitted through 
political podcasts. This single item was rated according to the Likert scale from 1 (never) to 4(very often).

\section{Control Variables}

News media use was measured by the amount of time respondents spent on printed newspapers, TV, Internet newspapers including portals and online version of traditional newspapers, and SNS per day. Each item was rated according to the Likert scale from 1 (never) to 6 (more than 2 hours). The mean and standard deviation of each variable is following: printed newspapers $(\mathrm{M}=1.73, S D=1.05)$, TV $(\mathrm{M}=3.19, S D=1.11)$, Internet newspapers $(\mathrm{M}=3.29, S D=1.11)$, and SNS $(\mathrm{M}=2.67, S D=1.23)$.

Political variables are also controlled. Political ideology adapted from Min (2014) was measured by respondents' subjective political orientation. It ranged from conservative (1) to progressive (7). Degree of interest in politics drawn from Kim and Yang (2013) was measured by the extent to which respondents were interested in political issues, governmental policy, political party, politicians, and TV political debate. Each item was measured on a 4-point Likert scale (1=never to $4=$ very much) and averaged $(\alpha=0.86, \mathrm{M}=2.79, S D=0.58)$. Political efficacy was measured by the extent of participants' agreement on three items such as "I have the capacity to understand political issues and participate in politics" and "My political interest and participation will be helpful for desirable management of state affairs." All items were rated on a 5-point scale (1=strongly disagree to $5=$ strongly agree) and averaged $(\alpha=0.83, \mathrm{M}=3.62, S D=0.67)$. Items were drawn from Kim (2009) and Jung et al. (2011).

In addition to these variables, gender, age and income were used as control variables. The monthly average income of a family (Korean money unit) was rated on a 6 -point Likert scale ( $1=$ less than $1,000,000$ won $\sim 6=$ more than $5,000,000$ won); $\mathrm{M}=4.47, \mathrm{SD}=1.43$ ).

\section{Analysis}

To analyze the effect of motivations for podcast and news podcast on offline and online political participation, we used hierarchical multiple regression analysis with SPSS 22.0. Demographic variables were entered first, followed by political variables, news media use, motivations for podcast use, news podcast, and online or offline participation. Next, we used PROCESS to analyze the mediation effect of political discussion in the relationship between news podcast use and political participation, controlling for political interest and efficacy.

\section{Results}

Table 2 shows how input variables affect offline political participation. Among them, online participation had the greatest influence on it $(\beta=0.346$, 
$\mathrm{p}<0.001$ ). People who participate in activities online are more likely to attend political rallies or participate in a signature campaign. The extent of discussions on issues which was broadcast on podcast was also associated with offline participation $(\beta=0.113, \mathrm{p}<0.001)$, supporting hypothesis 3 . However, news podcast use was not related to political participation. Therefore, hypothesis 1 that news podcast use will affect offline participation was not supported. In addition, any motivation for podcast use had no significant relationships with participation. Among control variables, only gender and political ideology had a slightly significant effect. The model explained $21.9 \%$ of variance in offline political participation $\left(\mathrm{F}=81.087, p<0.001\right.$; Adjusted $\left.\mathrm{R}^{2}=0.219\right)$.

Table 2. Hierarchical Regression Analysis Predicting Offline Political Participation

\begin{tabular}{|c|c|}
\hline Variables & Standardized regression coefficient \\
\hline \multicolumn{2}{|l|}{ Block 1. Demographics } \\
\hline Gender $($ female $=1)$ & $0.081^{*}$ \\
\hline Age & -0.044 \\
\hline Income & 0.023 \\
\hline$\Delta \mathrm{R}^{2}$ & 0.013 \\
\hline \multicolumn{2}{|l|}{ Block 2. Political variables } \\
\hline Political ideology & $0.065^{+}$ \\
\hline Political interest & 0.044 \\
\hline Political efficacy & 0.055 \\
\hline$\Delta \mathrm{R}^{2}$ & 0.081 \\
\hline \multicolumn{2}{|l|}{ Block 3. News media use } \\
\hline Newspaper & 0.035 \\
\hline TV & -0.020 \\
\hline Internet & -0.038 \\
\hline SNS & 0.064 \\
\hline$\Delta \mathrm{R}^{2}$ & 0.027 \\
\hline \multicolumn{2}{|c|}{ Block 4. Motivations for podcast use } \\
\hline Entertainment & 0.012 \\
\hline Access & 0.032 \\
\hline Information seeking & 0.025 \\
\hline Alternative media & -0.003 \\
\hline$\Delta \mathrm{R}^{2}$ & 0.007 \\
\hline \multicolumn{2}{|l|}{ Block 5. News podcast } \\
\hline Use time & -0.018 \\
\hline Discussion & $0.113^{* *}$ \\
\hline$\Delta \mathrm{R}^{2}$ & 0.023 \\
\hline Block 6. Online participation & $0.346^{* * *}$ \\
\hline$\Delta \mathrm{R}^{2}$ & 0.086 \\
\hline $\mathrm{R}^{2}$ & 0.237 \\
\hline Adjusted $\mathrm{R}^{2}$ & 0.219 \\
\hline
\end{tabular}

${ }^{+} p<0.1,{ }^{*} p<0.05, * * p<0.01, * * * p<0.001$

Table 3 indicates the predictors of online political participation. Offline participation and political interest were strongly associated with online participation (each $\beta=0.294, p<0.001$ and $\beta=0.207, p<0.001$ ). Among news media use, 
newspaper, Internet and SNS were positively related to online activities such as online petition or sharing messages. Political discussion was also a critical predictor as it was in offline participation, supporting hypothesis 4. However, any motivations for podcast use were not related to online participation. Unexpectedly, the use time of news podcast was negatively associated with online participation. Therefore, hypothesis 2 that podcast use is positively related to online participation was not supported. The model explained $33.8 \%$ of variance in offline political participation $\left(\mathrm{F}=81.087, p<0.001\right.$; Adjusted $\left.\mathrm{R}^{2}=0.338\right)$.

Table 3. Hierarchical Regression Analysis Predicting Online Political Participation

\begin{tabular}{|c|c|}
\hline Variables & $\begin{array}{c}\text { Standardized regression } \\
\text { coefficient }\end{array}$ \\
\hline \multicolumn{2}{|l|}{ Block 1. Demographics } \\
\hline Gender $($ female $=1)$ & -0.016 \\
\hline Age & 0.018 \\
\hline Income & -0.025 \\
\hline$\Delta \mathrm{R}^{2}$ & 0.003 \\
\hline \multicolumn{2}{|l|}{ Block 2. Political variables } \\
\hline Political ideology & -0.020 \\
\hline Political interest & $0.207^{* * *}$ \\
\hline Political efficacy & $0.071^{*}$ \\
\hline$\Delta \mathrm{R}^{2}$ & 0.147 \\
\hline \multicolumn{2}{|l|}{ Block 3. News media use } \\
\hline Newspaper & $0.091^{* *}$ \\
\hline TV & -0.023 \\
\hline Internet & $0.108^{* *}$ \\
\hline SNS & $0.186^{* * *}$ \\
\hline$\Delta \mathrm{R}^{2}$ & 0.102 \\
\hline \multicolumn{2}{|c|}{ Block 4. Motivations for podcast use } \\
\hline Entertainment & -0.058 \\
\hline Access & 0.019 \\
\hline Information seeking & 0.060 \\
\hline Alternative media & 0.002 \\
\hline$\Delta \mathrm{R}^{2}$ & 0.007 \\
\hline \multicolumn{2}{|l|}{ Block 5. News podcast } \\
\hline Use time & $-0.069^{*}$ \\
\hline Discussion & $0.101^{* *}$ \\
\hline$\Delta \mathrm{R}^{2}$ & 0.021 \\
\hline Block 6. Offline participation & $0.294^{* * *}$ \\
\hline$\Delta \mathrm{R}^{2}$ & 0.073 \\
\hline $\mathrm{R}^{2}$ & 0.353 \\
\hline Adjusted $\mathrm{R}^{2}$ & 0.338 \\
\hline
\end{tabular}

${ }^{*} p<0.05,{ }^{* *} p<0.01,{ }^{* * *} p<0.001$

Drawing on the communication mediation model, we analyzed the path from news podcast use to participation mediated by political discussion, controlling for political interest and efficacy. We applied PROCESS model 4 (5,000 bootstrap samples, 95\% CIs). The result showed that news podcast use did not have a 
significant direct effect on offline participation, but had an indirect effect (see Figure 1). That is, news podcast promoted political discussion $(\beta=0.217, p<.001$, $\mathrm{CIs}=[0.093,0.182])$, which in turn had a positive influence on political participation $(\beta=0.180, p<.001, \mathrm{CIs}=[0.173,0.416])$. This indirect effect was statistically significant $(\mathrm{CIs}=[0.021,0.064])$. This result indicates that political discussion mediated between news podcast and offline political discussion. Thus, hypothesis 5 that political discussion will be a mediating variable between news podcast use and offline political participation was supported.

Figure 1. The Effect of News Podcast Use on Offline Participation in Mediation of Political Discussion

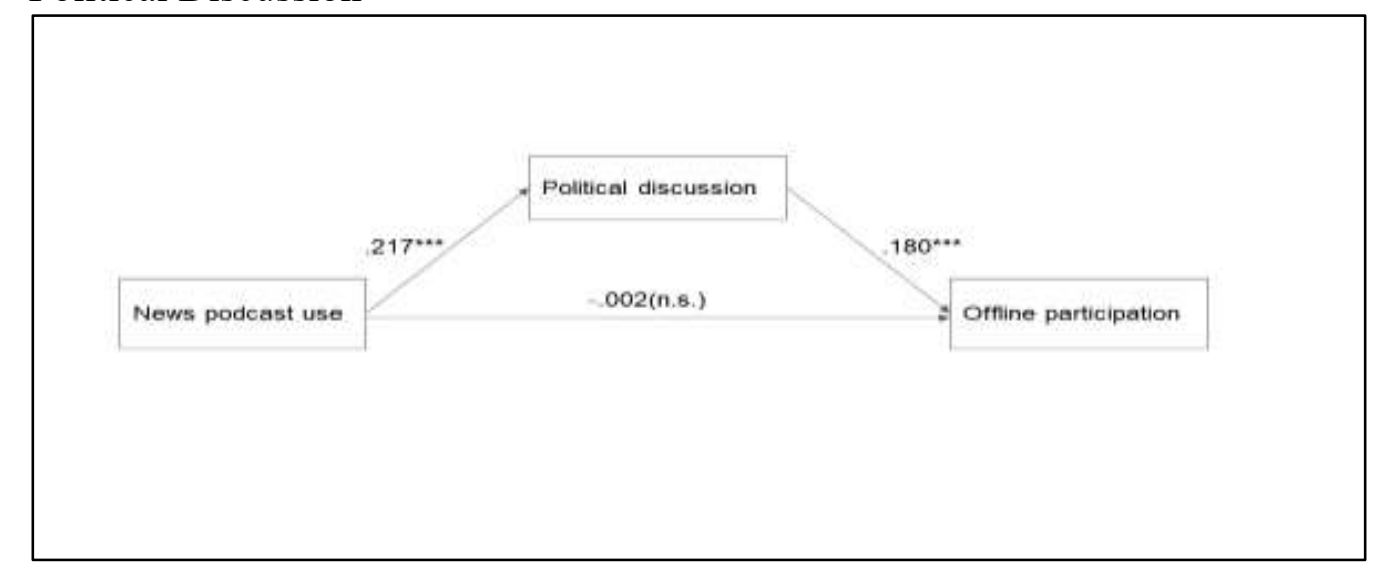

Figure 2 indicates the effect of news podcast use on online participation in mediation of political discussion. The direct effect of news podcast use on online participation was not significant $(\mathrm{CIs}=[-0.051,0.031])$. On the contrary, political discussion was found to be a mediated variable between news podcast and online participation, which supported hypothesis 6. That is, news podcast affected political discussion positively, which in turn was related to online participation $(\beta=0.168, p<.001, \mathrm{CIs}=[0.089,0.221])$. Thus, the indirect effect of news podcast on online participation was confirmed (CIs $=[0.018,0.058])$.

Figure 2. The Effect of News Podcast Use on Online Participation in Mediation of Political Discussion

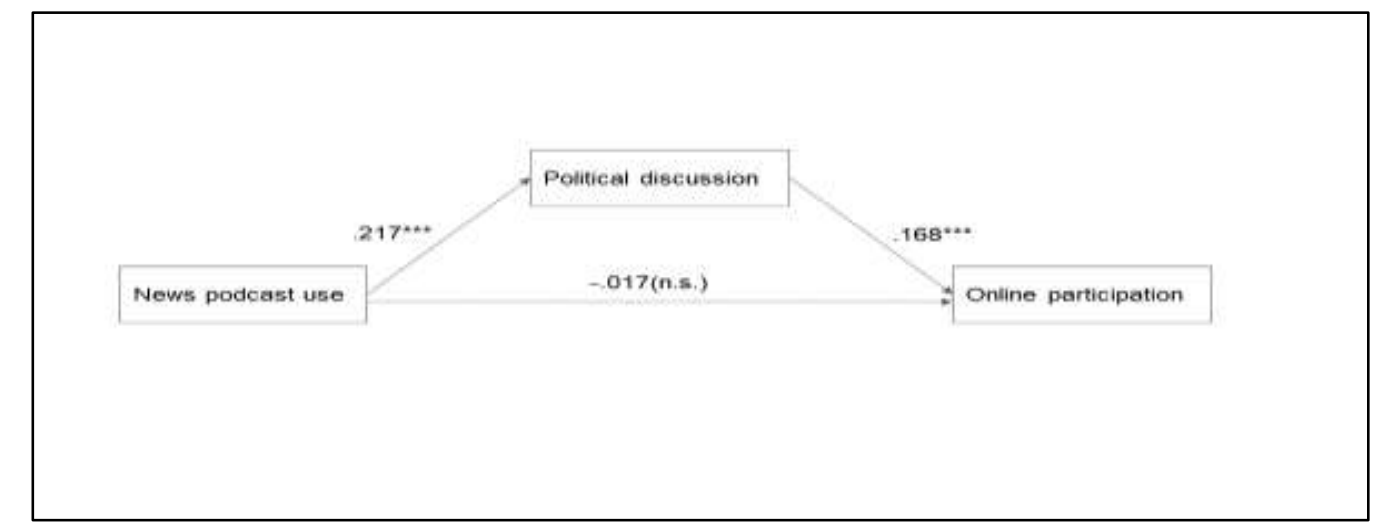




\section{Conclusion}

Now news podcasts are popular in Korea. This popularity is partly attributed to low credibility of mainstream media. Thus, many Korean people depend on SNS or podcasts for information. In this study, alternative media motive was one of four motives of podcast use. This indicates that users of news podcast use it to obtain information which mainstream media cannot transmit.

This study analyzed the predictors of offline and online political participation, focusing on motives and use of podcasts. Overall, the results showed that motivations were not associated with political participation. Furthermore, the time spent on news podcast was not a predictor of offline participation. Rather, it was negatively associated with online participation. On the other hand, discussion with people about current events or public issues was a critical predictor of political participation offline as well as online. This result indicates that talking about issues and sharing them with others are important in the promotion of political behaviors. Podcasts are an open platform for communication where people can explore and discuss issues that interest or concern them (Vrikki and Malik, 2019). This interactive medium activates political discussions, which might lead to political participation.

Offline participation and online participation were intimately related to each other. With the development of technology, participation on line has been active.

Drawing on the communication mediation model, this study tested the mediating role of political discussion between news podcast use and participation. Thus, it was confirmed that the use of news podcast was positively associated with discussion, which led to offline and online participation. That is, the time spent on news podcast was not directly related to participation. Rather, it was indirectly associated with offline and online participation by way of political discussion. This result supports communication mediation model and previous studies related to it. It also implies that the model can applied in the medium of podcast. Until now, there have been few studies which applied the communication mediation model to news podcasts. In this respect, this study is meaningful. It showed that political discussion could play a mediating role between news podcast use and offline/ online participation. Therefore, discussion needs to be revitalized to promote political activities.

Despite this contribution, this study has several limitations. First of all, it did not compare news podcast users and non-users. Future studies need to compare how much different users and non-users are in their political behaviors and attitudes.

\section{References}

Ardèvol-Abreu, A., Diehl, T., Gil de Zúñiga, H. (2017). Antecedents of internal political efficacy incidental news exposure online and the mediating role of political discussion. Politics, 39(1), 1-19.

Bai, S. Y. (2015). A study on the utilization of social media for the revitalization of youth culture. Sejong, Korea: National Youth Policy Institute. 
Bottomley, A. J. (2015). Podcasting: a decade in the life of a "new" audio medium: introduction. Journal of Radio \& Audio Media, 22(2), 164-169.

Chadha, M., Avila, A., Gil de Zúñiga, H. (2012). Listening in: building a profile of podcast users and analyzing their political participation. Journal of Information Technology \& Politics, 9(4), 388-401.

Chan, M., Chen, H-T, Lee, F, L. F. (2017). Examining the roles of mobile and social media. In political participation: a cross-national analysis of three Asian societies using a communication mediation approach. New Media \& Society, 19(12), 20032021.

Cho, J., Shah, D. V., McLeod, J. M., McLeod, D. M., Scholl, R. M., Gotlieb, M. R. (2009). Campaigns, reflection, and deliberation: advancing an O-S-R-O-R model of communication effects. Communication Theory, 19(1), 66-88.

Chung, C. (2019). Korea's far-right disinformation industry targets older conservatives. Retrieved from: https://codastory.com/disinformation/disinfo-newsletter/korea-farrig ht-youtube/. [Accessed 13 September 2020.]

Gil de Zúñiga, H., Jung, N., Valenzuela, S. (2012). Social media use for news and individuals' social capital, civic engagement and political participation. Journal of Computer-Mediated Communication, 17(3), 319-336.

Gil de Zúñiga, H., Diehl, T., Huber, B., Liu, J. H. (2019). The citizen communication mediation model across countries: a multilevel mediation model of news use and discussion on political participation. Journal of Communication, 69(2), 144-167.

Hao, X., Wen, N., George, C. (2014). News consumption and political and civic engagement among young people. Journal of Youth Studies, 17(9), 1221-1238.

Hwang, H., Kim, J. (2012). A study on the podcast usage and political participation of voters in their twenties in Seoul: a case study of listening i'm a petty trickster. The Journal of Social Science, 19(3), 151-184.

Jung, N., Kim, Y., Gil de Zúñiga, H. (2011). The mediating role of knowledge and efficacy in the effects of communication on political participation. Mass Communication and Society, 14(4), 407-430.

Kim, M. (2009). The effects of participation in the youth assembly of Republic of Korea on democratic attitude. Politics \& information Studies, 12(2), 119-142.

Kim, E., Yang, S. E. (2013). The new citizenship of digital natives and the influence of network media. Korean Journal of Journalism \& Communication Studies, 57(1), 305-334.

Korea Press Foundation, Reuters Journalism Institute (2018). Digital news report Korea. Seoul, Korea: Korea Press Foundation \& Reuters Journalism Institute.

Lee, H. (2012). Communication mediation model of late-night comedy: the mediating role of structural features of interpersonal talk between comedy viewing and political participation. Mass Communication and Society, 15(5), 647-671.

Lee, J. (2017). The effects of podcast usage and perceptions of podcast advertising on the purchase intention for products in podcast advertising and the execution intention for podcast advertising. Korean Journal of Broadcasting and Telecommunication Studies, 31(4), 170-204.

Lee, D., Hwang, S. (2013). The usage motivation of political podcast <Naneun Ggomsuda> and its influence in on-and offline political participation: based on the survey of 2040 users in Seoul. Media, Gender \& Culture, 26, 141-175.

Lee, J., Kuem, H. (2012). A study on the impacts of using politics podcasts on on/off-line political participation: focused on motivations for using politics podcasts by the users in their 20s, political psychology variables and on/off-line political participation variables. Korean Journal of Journalism \& Communication Studies, 56(5), 163-189.

Lee, C., Ryu, S. J. (2013). The effect of <Nanun KKomsuda > on the political socialization 
of high school and university students: focusing on political interest, political efficacy, political knowledge, and political participation. Journal of Communication Science, 13(3), 490-526.

Li, X., Chan, M. (2017). Comparing social media use, discussion, political trust and political engagement among university students in China and Hong Kong: an application of the O-S-R-O-R model. Asian Journal of Communication, 27(1), 6581.

Markman, K. M., Sawyer, C. E. (2014). Why pod? Further explorations of the motivations for independent podcasting. Journal of Radio \& Audio Media, 21(1), 20-35.

McClung, S., Johnson, K. (2010). Examining the motives of podcast users. Journal of Radio \& Audio Media, 17(1), 82-95. doi: 10.1080/19376521003719391

Min, Y. (2014). The intertwining of news and entertainment: the effects of political podcasts in the 2012 Korean presidential election. Korean Journal of Journalism \& Communication Studies, 58(5), 70-96.

Min, Y. (2015). Political satire and participatory citizenship: effects of political podcasts on political participation. Korean Journal of Broadcasting \& Telecommunication Studies, 29(3), 36-69.

Park, C. (2017). Citizen news podcasts and engaging journalism: the formation of a counter-Public sphere in Korea. Pacific Journalism Review, 23(1), 245-262.

Perks, L, G., Turner, J. S. (2019) Podcasts and Productivity: a qualitative uses and gratifications study. Mass Communication and Society, 22(1), 96-116.

Pew Research Center (2019). Audio and podcasting fact sheet. Retrieved from: https://ww w.journalism.org/fact-sheet/audio-and-podcasting/. [Accessed 13 September 2020.]

Podtrac (2019). Podcast industry ranking top 20 podcasts us audience: August 2019. Retrieved from: http://analytics.podtrac.com/industry-rankings. [Accessed 13 September 2020.]

Rubin, A. M., Step, M. M. (2000). Impact of motivation, attraction, and parasocial interaction on talk radio listening. Journal of Broadcasting \& Electronic Media, 44(4), 635-654.

Shah, D. V., Cho, J., Nah, S., Gotlieb, M. R., Hwang, H., Lee, N. et al. (2007). Campaign ads, online messaging, and participation: extending the communication mediation model. Journal of Communication, 57(4), 676-703.

Shah, D. V., McLeod, D. M., Rojas, H., Cho, J., Wagner, M. W., Friedland, L. A. (2017). Revisiting the communication mediation model for a new political communication Ecology. Human Communication Research, 43(4), 491-504.

Song, I. (2012). The effects of <Naneun Ggomsuda> on college students' political knowledge, political self-efficacy, and political participation. Political Communication Studies, O(27), 101-147.

Valenzuela, S., Kim, Y., Gil de Zúñiga, H. (2011). Social networks that matter: exploring the role of political discussion for online political participation. International Journal of Public Opinion Research, 24(2), 163-184.

Vrikki, P., Malik, S. (2019) Voicing lived-experience and anti-racism: podcasting as a space at the margins for subaltern counterpublics. Popular Communication, 17(4), 273-287.

Yang, H., Dehart, J. L. (2016). Social media use and online political participation among college students during the US election 2012. Social Media + Society, 2(1), 1-18.

Zizi, P., Rubin, A. M. (2000) Predictors of internet use. Journal of Broadcasting \& Electronic Media, 44(2), 175-196. 